\title{
1 Bacterial invasion of the pancreas revealed after analyses of the pancreatic cyst fluids
}

3 Vilvapathy Narayanan ${ }^{1}$, Wesley K. Utomo ${ }^{1}$, Marco J. Bruno ${ }^{1}$, Maikel P. Peppelenbosch ${ }^{1}$, Sergey

$4 \quad$ R. Konstantinov ${ }^{1 *}$

$5 \quad{ }^{1}$ Department of Gasteroenterology and Hepatology

6 Erasmus MC - University Medical Center Rotterdam

$7 \quad$ 's Gravendijkwal 230

$8 \quad$ NL-3015 CE Rotterdam

9 The Netherlands

$10 \quad$ Phone : $\quad+31(0) 107032792$

$11 \quad$ Fax: $\quad+31-(0) 107032793$

12 E-mail: m.peppelenbosch@erasmusmc.nl

$14 *$ To whom correspondence should be addressed

Running head: Bacteria in Pancreatic cyst fluid

Keywords: 16S rRNA gene, pancreatic cyst fluid, cystic tumors, Fusobacterium spp., bacterial translocation

Acknowledgements: Hypothesis and experiment planning Sergey R konstantinov, experiment

21 execution and manuscript written by Vilvapathy Narayanan, Manuscript reviewed by Wesley K

22 Utomo, Sergey R Konstantinov, Marco J Bruno and Maikel P Peplenbosch. PCF fluid kindly

23 provided by Gastroenterologists Henri Braat, J.W. Poley, A.D. Koch. FFPE blocks kindly provided

24 by M. Doukas (Michael) pathology department, FFPE section were prepared by Juan Li 25 Gastroentrolgy \& Hepatology department, training and help in confocal microscopy provided by 
1 Gert-Jan Kremers and proteinase $\mathrm{K}$ was kindly provide by André Boonstra and Kim Kreefft

2 Gastroentrolgy \& Hepatology department

\section{Abstract}

7 The involvement of bacterial translocation (BT) in the promotion of carcinogenesis has gained a 8 considerable attention in the last years. At this point however BT has not been studied in the 9 context of pancreatic cystic lesions and their development into pancreatic ductal adenocarcinoma. 10 The aim of the study was to analyze if bacteria are present in pancreatic cyst fluid (PCF) collected 11 from patients with suspected pancreatic cysts. Total DNA was isolated from sixty nine PCF. The 12 occurrence of bacteria in PCF was analyzed using bacterial 16S rRNA gene-specific PCR-based 13 method followed by sequence identification and quantitative PCR assay tuned up to different 14 pathogenic and commensal human bacteria. Forty-seven out of sixty-nine samples (68\%) were 15 found positive for harboring bacterial 16S rRNA gene. Follow up sequencing analyses of the PCR 16 products revealed that bacterial species related to Fusobacterium spp., Bacteroides spp., and 17 Bacillus spp. were predominating the PCF samples. The results suggest that specific bacteria can translocate to the pancreas and become detectable in the PCF. 


\section{Introduction}

2 The incidence of pancreatic cystic lesions (PCL) in the general population is 2.4 percent.

3 Neoplastic pancreatic cysts represent a risk for developing pancreatic ductal adenocarcinoma ${ }^{1}$

4 (PDAC) and account for up to $5 \%$ of the total incidence of pancreatic cancerous lesions ${ }^{2,3}$. The

5 clinical challenge in PCL is to identify signs of progressive neoplastic transformation in order to

6 perform a surgical resection before a malignancy develops.

7 The vast majority of cysts nowadays are asymptomatic and coincidental finding at cross sectional

8 imaging done for other reasons than cyst related symptoms. The percentage of cystic lesions being

9 resected is increasing with the clinical intention of preventing the development of PDAC. Different

10 types of cystic lesions are presently characterized by Grutzmann et. al., and Farrell et. al., which

11 include the intra-ductal papillary mucinous neoplasm (IPMNs), mucinous cystic neoplasms

12 (MCN), serous cyst adenomas (SCA), and pseudocysts ${ }^{4,5}$. IPMN's and MCN's pose a risk of

13 developing into carcinoma of which IPMNs are being more prevalent compared with MCN's ${ }^{2,6}$.

14 IPMNs are further classified as main branch, side branch or mixed types, based on the extent of

15 involvement of the pancreatic ductal system ${ }^{5}$. Presently, there are no validated biomarkers to

16 identify cystic lesions that require surgical resection. Although only up to three percent of the PCL

17 patients would develop cystic lesions to malignancy, ten percent of the PCL patients are resected

185 suggesting the need for more superior clinical tests and better patients' stratification prior to 19 surgery.

Currently, the decision for resection of PCL and/or continued monitoring are made according to the Sendai guidelines after evaluation of different clinical tests ${ }^{7-9}$. The available clinical tests include different biochemical analysis, cytology, pathological identification, endoscopic ultra sonography (EUS), and radiological diagnosis such as endoscopic retrograde cholangiopancreatography (ERCP), magnetic resonance cholangiopancreatography (MRCP) and whole body computerized tomography (CT). The inter-observer agreement, however, within and between different modalities remains moderate. Therefore, a set of preoperative biochemical analyses have been increasingly used in clinical decision making. This includes the study of cyst fluids and serum for the characteristic presence of carcinoembryonic antigen (CEA), cancer antigen 19.9 (CA-19.9), tumour associated glycoprotein 72-4 (CA-72-4), cancer antigen 15-3 (CA- 
1 tests are based on specific analyses of different genetic modalities like K-RAS mutation and 2 miRNA, but are still under investigation awaiting further clinical validation 2,6,12,13. Though different diagnostic tests could help in decision making, none of them is sensitive and specific enough to make the right decisions for all patients involved. Additional markers are therefore are urgently needed to improve the management of PCL.

The human gut microbiome has emerged recently as an important environmental factor

7 linked to the development of different intestinal and extra-intestinal malignancies ${ }^{14-16}$. Several members of the intestinal microbiome have been implicated in the bacterial translocation (BT) that could occur during different diseases of the pancreas ${ }^{17-21}$. Numerous studies suggest that BT takes place via the mesenteric lymph nodes route, followed by hepatic portal route, and trans mural or biliary or duodenopancreatic reflux ${ }^{18}$. This may initiate and/or accelerates intestinal leakage with a subsequent lowering of host immune response followed by dissemination of commensal gut microbiota and their by-products to other organs leading to sepsis and major multiple organ failures ${ }^{21,22}$. BT has been demonstrated in induced acute pancreatitis in mice and other animal models where BT takes place immediately towards the pancreatic duct causing necrosis in the

exocrine system of pancreas ${ }^{19,23}$. Most of the BT has been described to originate from the small intestine rather than from the colon ${ }^{19}$. BT-associated intestinal pathobionts include different strains belonging to Escherichia coli, Enterobacter cloacae, Enterobacter fecalis, Proteus mirabilis, and Pseudomonas species that have been involved in the necrotizing and acute pancreatitis ${ }^{18}$. Although there is ample evidence that BT takes place in various pancreatic diseases, not much has been studied nor understood about the bacterial presence in pancreatic cyst and/or cyst fluids. In this discovery phase study we have attempted to establish the bacterial occurrence in the pancreatic cystic lesions.

\section{Materials and Methods}

Patient samples and Pancreatic cyst fluid collection. A cohort of 103 patients with suspected cystic lesions was established between the period of 2008-2013 of which sixty nine samples were randomly selected for this discovery phase study (Table 1). The pancreatic cyst fluids (PCF) were collected after a signed informed consent from these patients who were undergoing endoscopic ultra sound fine needle aspiration (EUS-FNA) at the department of Gastroenterology \& 
1 Hepatology, Erasmus MC, The Netherlands. The PCF were collected, immediately transferred to 2 the lab and stored at $-150^{\circ} \mathrm{C}$.

DNA isolation. Approximately $300 \mu \mathrm{l}$ from sixty nine PCF samples were used for total DNA isolation. After bead beating (Fast Prep ${ }^{\circledR}-24$ Instrument) the supernatant and pellet were separated by centrifugation at $13000 \mathrm{rpm}$ for $1 \mathrm{~min}$ and used for total DNA isolation using the Wizard DNA isolation kit as specified by the manufacturer's protocol (Catalogue no. A1620, Promega BNL B.V, The Netherlands). Isolated DNA was equilibrated in the DNA rehydration solution from the kit and quantified on nanodrop-2000 spectrophotometer (Isogen Life Science BV, De Meern, The Netherlands). PCF DNA was diluted to $1 \mathrm{ng} / \mu \mathrm{l}$ for the PCR analyses and subsequently stored at $20^{\circ} \mathrm{C}$.

(q)PCR analyses. Total DNA isolated from the PCFs were used for bacterial 16S RNA gene detection using both conventional PCR and qPCR. For the conventional PCR based method GoTaq $^{\circledR}$ Flexi DNA polymerase kit was used (Promega BNL B.V, The Netherlands). qPCR was performed on IQ5 machine (Biorad, Bio-Rad Laboratories, Inc. Hercules, CA, United States of America) using Syber Green amplification kit (SYBR Select master mix, CFX, ABI, Life technologies, the Netherlands). All primers are listed in Table 2. All the primers were analysed and confirmed for the specificity to bacterial $16 \mathrm{~S}$ rRNA and mismatch with the human mitochondrial 16S rRNA. 16S rRNA gene products from Acinitobacteria spp., Anaerococcuss spp., Bacillus spp., Bacteroides spp., F. nucleatum, Propionibacterium spp. and Staphylococcus spp. were used to generate PCR standards from $10 \mathrm{ng}$ to $0.00001 \mathrm{ng}$ concentrations thereby achieving total of seven standards. Water was used as negative control.

16S RNA gene sequencing analyses. Classical Sanger sequencing method was done in order to identify the bacterial 16S rRNA genes present in the PCF. The PCR products generated from universal primers of $16 \mathrm{~S}$ rRNA $16 \mathrm{~S}$ bacterial gene were sequenced and then after identification of specific bacteria which are pathogenic commensals and as well involved in cancer development were used for further sequencing. The Fusobacterium spp., Bacteroides spp., Anaerococcus spp., Acinitobacteria spp., Propionibacterium spp., and Staphylococcus spp. Specific 16S rRNA primers were used and sequenced (Table 2) through LGC Genomics GMBH, Germany.

Fluorescent In-situ Hybridization. The depraffinization of the slides were performed as the protocol used in our lab ${ }^{24}$, once depraffinized the tissues slides are subjected to PBS washing for 
one minute. Modified proteinase $\mathrm{K}$ treatment was done under incubation at $45^{\circ} \mathrm{C}$ for 30 minutes to reduce the background staining (proteinase $\mathrm{K}-20 \mu \mathrm{g} / \mathrm{ml} \mathrm{1:10} \mathrm{dilution)} \mathrm{(Sigma} \mathrm{Aldrich,} \mathrm{the}$ Netherlands) ${ }^{25}$. The slides are then dehydrated for $3 \mathrm{~min}$ in 50, 70, and finally $96 \%$ ethanol. 500 microliters of hybridization buffer $(0.9 \mathrm{M} \mathrm{NaCl}, 20 \mathrm{mM}$ Tris- $\mathrm{HCl}$ [pH 7.5] $0.1 \%$ [wt/vol] sodium dodecyl sulfate) were applied and incubated at $37^{\circ} \mathrm{C}$ for 30 minutes. The hybridization buffer is washed off in the prewarmed PBS at $37^{\circ} \mathrm{C}$ and new pre-warmed hybridization buffer is added with the FITC labelled probes containing 1 picomole of FITC-labeled 16S rRNA probes (EUB338 and $F$. nucleatum) was applied and incubated at $37^{\circ} \mathrm{C}$ for 18 hours. After hybridization, the slides were washed in $50 \mathrm{ml}$ washing buffer $(0.4 \mathrm{X}$ SSC buffer for 2 minutes followed with $2 \mathrm{X}$ SSC buffer for 1 minute, SSC buffer prepared as per the protocol by Zordan A et.al ${ }^{25}$ and washed with PBS $1 \mathrm{X}$ for 1 minute and DAPI $(1 \mu \mathrm{g} / \mathrm{ml})$ is added for counter staining of the nucleus and stained for exactly 3 minutes. The slides are washed with PBS 1X and air dried. All the staining are done in dark. The air dried slides are then examined using confocal microscope (LEICA, The Netherlands).

Statistical methods. All the statistical analysis were done using excel and Graphpad Prism 5.0.

The CT values in $\mathrm{X}$ axis were plotted against the serially diluted standards in $\mathrm{Y}$ axis to find the intercept $\mathrm{Y}$ using the exponential trend line for the CT values as per the excel formula. The $\mathrm{R}^{2}$ is also determined for the same plot. The $\mathrm{Y}$ intercept is used to calculate the ng of 16S rRNA for the unknown samples of Fusobacterium spp., Bacteroides spp., Anaerococcus spp., Acinitobacteria spp., Propionibacterium spp., and Staphylococcus spp.. Once the ng for each sample is obtained they are used for calculating absolute copy number of 16s rRNA using the following formula,

$$
\left.\left(\mathrm{SX}_{1} * 6.02 \times 10^{14}\right)+\mathrm{PX} 1 * 6.02 \times 10^{14}\right)
$$

Where in $\mathrm{SX}_{1}$ and $\mathrm{PX}_{1}-\mathrm{S}-$ stands for supernatant, $\mathrm{P}-$ stands for the pellet, $\mathrm{X}_{1}-$ stands for the sample 1, $6.02 \times 10^{14}$ - nano gram to Daltons, $3.37 \times 10^{2}$ molecular weight of one nucleotide in Daltons, Q1 - stands for the qPCR - product in number of nucleotides. The final conversion of $16 \mathrm{~S}$ rRNA copy number to $1 \mathrm{ml}$ of PCF is calculated via $16 \mathrm{~S}$ rRNA copy number multiplied by 


\section{Results}

Study sample characteristics. Sixty nine PCF samples were used for this study (Table 1). PCF were characterized as different types of IPMN's (39.1\%), which included main branch IPMN (2.9\%), mixed type IPMN's (5.8\%), side branch IPMN's (17.4\%) and multifocal side branch IPMN's (5.8\%), and unclassified IPMN's (7.2\%). Another types of PCF included in the study were mucinous cystic neoplasms (18.8\%), pseudocysts (13.0\%), serous cyst adenomas (13.0\%). Finally, various other types of cystic lesions, gastrointestinal stromal tumour (GIST), neuroendocrine tumour (NET), and PCF without a definite clinical diagnosis were lumped into a separate category “other” PCF (15.9\%) Table 1.

Bacterial DNA presence in pancreatic cyst fluids. We have found that $47(68.11 \%)$ of the 69 samples were positive for bacterial DNA originating from different bacteria (Table 3). Various PCFs harboured different percentage of positive samples ranging from $69.2 \%$ of all MCN's, followed by IPMN's with 66.7\% and pseudocysts (66.7\%), SCA's (55.6\%), whereas in the group of others which included GIST, NET and clinically undefined samples were $71.4 \%$ predominantly positive for bacterial DNA (Table 6). This confirms the bacterial DNA present in the PCF's.

Bacterial DNA quantification in pancreatic cyst fluids. We have used qPCR experiments to confirm the presence of typical intestinal bacteria using specific primer sets targeting Bacteroides spp., Anaerococcus spp., Acinitobacterium spp., Propionibacterium spp., and selected pathobionts including F. nucleatum, and Staphylococcus spp. The copy number quantified for the total bacteria and the specific bacteria selected based on 16S rRNA qPCR were adjusted to ml of pancreatic cyst fluid are listed in Table 4. Based on the copy number the 16S rRNA were ranked the bacteria as represented in Table 5, which shows the pseudocysts $\left(5.07 \times 10^{8}\right)$ shows the highest copy number for bacteria and the lowest also seen in SCA $\left(3.53 \times 10^{5}\right)$, corroborating the presence of bacteria in pseudocysts as seen in earlier reports. The average bacterial $16 \mathrm{~S}$ rRNA copy number $/ \mathrm{ml}$ of PCF was $1.08 \times 10^{7}$ with most occurring in pseudocysts $\left(5.71 \times 10^{7}\right)$ followed with $\mathrm{MCN}\left(1.15 \times 10^{7}\right)$, IPMN $\left(2.04 \times 10^{6}\right)$ others (GIST, NET and clinically undefined - $\left.1.92 \times 10^{6}\right)$, and SCA $(7.91 \times$ $10^{5}$ ) (Figure 1). One sample in pseudocysts, showed an abnormal bacterial load of $5.07 \times 10^{8}$ compared to other samples (Table 4). Similarly, there are change in the number of 16S rRNA copy number between various grades of dysplasia (graded according to the most atypical area in the lesion) in IPMN in the decreasing order: $2.46 \times 10^{6}$ in no dysplasia, low grade dysplasia have 1.75 
$1 \times 10^{6}$, Moderate dysplasia $9.67 \times 10^{5}$ and carcinoma in situ $8.30 \times 10^{5}$ (Fig 2, no statistical

2 difference). qPCR on PCF with mucinous cystic neoplasms have also demonstrated a higher number of bacterial $16 \mathrm{~S}$ rRNA gene in the samples where no dysplasia is present (Fig 3).

4

When the partial gene bacterial 16S rRNA (1464 nucleotide) normal PCR were conducted using universal primers (table-2) only $68.11 \%$ of the samples showed positive bacterial population presence. Whereas the quantification via qPCR of bacterial 16S rRNA (193 nucleotides) primers shown in table-2, shows presence of bacterial $16 \mathrm{~S}$ rRNA in $100 \%$ of the samples.

Sequencing of the bacterial 16S rRNA sequences. PCR products generated using universal 16S rRNA, and primers specific for F. nucleatum, Bacteriodes spp., Anerococcus spp., Acinitobacterium spp., Propionibacterium spp., and Staphylococcus spp. were subjected to sequencing to confirm the qPCR results (Table 6). The sequencing results have demonstrated that F. nucleatum is present in 13 out of all $69 \mathrm{PCF}$ samples (18.84\%). Other predominating bacterium involved in PCF was Bacillus spp. which was present in 16 out of 69 (23.19\%) samples. The presence of other bacteria was also noted which included Ruminococcus spp., Staphylococcus spp., Caldimonas spp., Arthrobacter spp., Acinetobacter spp., Bacteroides spp., Orpinomyces spp. Anaerococcus spp (combined data from Tables 3 and 6).

Fluorescent In-situ Hybridization (FISH). FISH was used as an additional analysis to confirm the presence of bacteria in PCF. Selected slides were blindly analysed checked and scored for bacterial presence by two personal specialized in confocal microscopy. We have confirmed it by the confocal imaging of the FISH slides for the bacterial presence Figure 4. Importantly, our control samples, negative for bacterial presence in the PCF's were also negative in the tissue slices generated after resection (data not shown). On the opposite side, the tissue samples from patients with PCF positive for bacterial DNA were also positive for bacterial presence in the tissue, the cysts borders and the duct borders (Figure 4).

\section{Discussion}

In the current study we have demonstrated that 68 percent of the PCF harbour different types of bacteria. The possible BT into the pancreatic cysts involve also bacteria related to $F$. nucleatum implicated in adenoma to carcinoma transformation in epithelial cells ${ }^{26}$. Although 
1 EUS-FNA is not a sterile procedure, 1/3 (32 percent) of the PCF samples were negative for 2 bacterial DNA on our cultivation-independent bacteriological findings. Nonetheless EUS-FNA 3 limitations for bacterial analyses need to be discussed. Before sampling cyst fluid, the needle tip 4 is exposed to the content in the stomach or gut lumen before being punctured through the gut wall 5 into the pancreatic cyst. The presence of bacterial 16S rRNA in all the 69 samples taken for this study, observed as in the qPCR is due to the above said reasons of EUS-FNA being an non-sterile procedure and also due to the bacterial products transferred via the other contaminants of the cyst

8 fluids, like blood which is plausibly carrying the bacteria DNA via the bacteria ingested macrophages and other immune cells. To nullify and further account for that when interpreting our data, we have performed confocal imaging for bacteria confirming that the tissue samples resected from patients with PCF positive for bacterial DNA were also positive for bacterial presence in the tissue. Furthermore, many bacteria in the stomach like H. pylori and streptococci were not found in our PCF analyses supporting the notion that specific bacterial community may be associated with PCF.

BT involvement into the pancreatic abscess, necrosis, pancreatitis, and pancreatic cyst have also been reported mainly in isolated case studies, but never in large cohort analyses ${ }^{22,27-29}$. Numerous case studies identified BT to pancreas were caused by the commensal bacteria and fungi. Pancreatic infections mainly arise from translocation of bacteria from the small bowl, and rarely from the colon and oropharyngeal route as demonstrated by study on Veillonella and Bifidobacterium spp. which were identified in pancreatic abscess ${ }^{28}$. A study of Brook et al., has identified 158 bacterial species from pancreatic abscess of which 77 isolates were aerobic and rest 81 were anaerobic bacteria ${ }^{30}$. Most commonly detected microorganisms in pancreatic pseudocysts include often not only opportunistic bacteria like E. coli, Enterobacter spp., Klebsiella spp., and Staphylococcus spp., but also fungal isolates including Candida albicans (15 case studies) ${ }^{27}$. Importantly, EUS FNAB procedure caused serious Clostridium perfringens infections in 5 patients leading to pancreatitis and pancreatic cyst formation, which required surgical interventions ${ }^{31}$. The study has illustrated the nature of the bacterial transfer from the early to mid-gut commensal bacteria to the pancreas. Yet none of these earlier studies have directly proved the presence of bacteria in the pancreatic cysts and its fluid. In the current study we have demonstrated that bacterial DNA is present in PCF. Although we do not have direct evidence that bacteria are alive in the PCF samples, the successful FISH analyses for some of the samples suggest that at least in 
1 part the bacterial population comprises of intact bacteria with undegraded 16S rRNA. PCF and the

2 pancreatic duct borders represent therefore a niche that may become colonized by specific bacteria as demonstrated in the study.

4 The interactions between commensal and/or pathogenic bacteria and their metabolic 5 products with hosts tissue can affect several diseases' progression ${ }^{27,29,32}$. Human serum derived

6 antibody response against oral bacteria Porphyromonas gingivalis ATTC 53978 has been 7 associated with an increased risk of pancreatic cancer by two folds ${ }^{33}$. Furthermore, a study of 8 Farell et.al., has showed that two oral bacteria, Neisseria elongata and Streptococcus mitis, can 9 differentiate between pancreatic cancer and normal cases with $96.4 \%$ sensitivity and $82.1 \%$ 10 specificity ${ }^{35}$. In the same study, the oral bacteria Granulicatella adiacens and Streptococcus mitis 11 differentiated between pancreatic cancer and pancreatitis with $85.7 \%$ sensitivity and $55.6 \%$ 12 specificity, similarly in colorectal cancer the difference in bacterial Operational Taxonomic Units 13 (OTU's) were found between the normal, adenomatous and cancerous population, resulting in 14 diagnosis of these three types in a person ${ }^{34-36}$. Analyses on the direct role of Helicobacter pyroli have shown that the bacterium was not associated with the development of pancreatic cancer ${ }^{37-40}$. Two other studies, however, support indirect association between $H$. pylori and pancreatic cancer risk. H. pylori may represent high risk for the individuals with non-O blood types because Helicobacter spp DNA was found in $75 \%$ patients with pancreatic adenocarcinoma and in $57 \%$ of patients with neuroendocrine cancer, and in $60 \%$ of patients with chronic pancreatitis ${ }^{41,42}$. Also the recent establishment of the role of $F$. nucleatum, Bacteriodes spp. in colorectal cancers in invivo and Citrobacter rodentium, in in-vitro conditions also shows the association of bacteria in general in cancer initiation and development ${ }^{26,33,36,43-46}$. Microbiomes roles is being established in other cancers like urothelial (Bacteriodes spp.) ${ }^{47}$ and prostate cancers (Propionibacterium spp) ${ }^{48,49}$, liver cancer where the gut microbial metabolites were involved in the liver cancer progression 50 .

26 Through this study we conclude, the bacterial presence was confirmed in the pancreatic cyst fluids, 27 and as well-established via their copy number of 16S rRNA, Sangers sequencing and fluorescent 28 in-situ hybridization. The kind of bacterial $16 \mathrm{~S}$ rRNA shown, prove they were translocated from 29 the mid and hind gut into the pancreas. Further analyses of the type of bacteria present in PCF 
1 can potentially help us to distinguish between various cyst types and the difference between the

2 various grades of dysplasia.

3 It may also help in understanding the mechanism, whether it is a epiphenomenon or direct effect

4 of how the presence of specific type of bacteria can potentiate the primary cystic lesions

5 progressing towards pancreatic cancer. Furthermore, the data also raise a question of whether the

6 bacterial population as seen in the pancreatic cyst fluid as well the cyst margins and duct margins

7 could be a possible commensals of the pancreatic duct rather than bacterial invasion/translocation.

8 A more comprehensive study is required for understanding this phenomenon.

9

10

11

12

13

14

15

16

17

18

19

20

21

22

23

24

25

26

27

28

29

30

31 


\section{References}

1. de Jong $\mathrm{K}$, Nio $\mathrm{CY}$, Hermans JJ, et al. High prevalence of pancreatic cysts detected by screening magnetic resonance imaging examinations. Clinical gastroenterology and hepatology : the official clinical practice journal of the American Gastroenterological Association. Sep 2010;8(9):806-811.

2. Matthaei $H$, Schulick RD, Hruban RH, Maitra A. Cystic precursors to invasive pancreatic cancer. Nature reviews. Gastroenterology \& hepatology. Mar 2011;8(3):141-150.

3. Wu BU, Sampath K, Berberian CE, et al. Prediction of malignancy in cystic neoplasms of the pancreas: a population-based cohort study. The American journal of gastroenterology. Jan 2014;109(1):121-129; quiz 130.

4. Grutzmann R, Niedergethmann M, Pilarsky C, Kloppel G, Saeger HD. Intraductal papillary mucinous tumors of the pancreas: biology, diagnosis, and treatment. The oncologist. 2010;15(12):1294-1309.

5. Farrell JJ, Fernandez-del Castillo C. Pancreatic cystic neoplasms: management and unanswered questions. Gastroenterology. Jun 2013;144(6):1303-1315.

6. Matthaei $\mathrm{H}$, Wylie $\mathrm{D}$, Lloyd MB, et al. miRNA biomarkers in cyst fluid augment the diagnosis and management of pancreatic cysts. Clinical cancer research : an official journal of the American Association for Cancer Research. Sep 1 2012;18(17):4713-4724.

7. Sawhney MS, Al-Bashir S, Cury MS, et al. International consensus guidelines for surgical resection of mucinous neoplasms cannot be applied to all cystic lesions of the pancreas. Clinical gastroenterology and hepatology : the official clinical practice journal of the American Gastroenterological Association. Dec 2009;7(12):1373-1376.

8. Goh BK, Thng CH, Tan DM, et al. Evaluation of the Sendai and 2012 International Consensus Guidelines based on cross-sectional imaging findings performed for the initial triage of mucinous cystic lesions of the pancreas: a single institution experience with 114 surgically treated patients. American journal of surgery. Aug 2014;208(2):202-209.

9. Tanaka M, Chari S, Adsay V, et al. International consensus guidelines for management of intraductal papillary mucinous neoplasms and mucinous cystic neoplasms of the pancreas. Pancreatology. 2006;6(1-2):17-32.

10. Khalid A, Brugge W. ACG practice guidelines for the diagnosis and management of neoplastic pancreatic cysts. The American journal of gastroenterology. Oct 2007;102(10):2339-2349.

11. Monkemuller KE, Harewood GC, Curioso WH, et al. Biochemical analysis of pancreatic fluid collections predicts bacterial infection. Journal of gastroenterology and hepatology. Nov 2005;20(11):1667-1673.

12. Kim JH, Eun HW, Kim KW, et al. Intraductal papillary mucinous neoplasms with associated invasive carcinoma of the pancreas: imaging findings and diagnostic performance of MDCT for prediction of prognostic factors. AJR. American journal of roentgenology. Sep 2013;201(3):565-572.

13. Khalid A, Zahid M, Finkelstein SD, et al. Pancreatic cyst fluid DNA analysis in evaluating pancreatic cysts: a report of the PANDA study. Gastrointestinal endoscopy. May 2009;69(6):1095-1102.

14. Qin J, Li R, Raes J, et al. A human gut microbial gene catalogue established by metagenomic sequencing. Nature. Mar 4 2010;464(7285):59-65.

15. Arumugam $\mathrm{M}$, Raes J, Pelletier $\mathrm{E}$, et al. Enterotypes of the human gut microbiome. Nature. May 12 2011;473(7346):174-180.

16. Konstantinov SR, Kuipers EJ, Peppelenbosch MP. Functional genomic analyses of the gut microbiota for CRC screening. Nature reviews. Gastroenterology \& hepatology. Dec 2013;10(12):741-745.

17. Kazantsev GB, Hecht DW, Rao R, et al. Plasmid labeling confirms bacterial translocation in pancreatitis. American journal of surgery. Jan 1994;167(1):201-206; discussion 206-207. 
18. Cicalese L, Sahai A, Sileri $\mathrm{P}$, et al. Acute pancreatitis and bacterial translocation. Digestive diseases and sciences. May 2001;46(5):1127-1132.

19. Fritz $\mathrm{S}$, Hackert $\mathrm{T}$, Hartwig $\mathrm{W}$, et al. Bacterial translocation and infected pancreatic necrosis in acute necrotizing pancreatitis derives from small bowel rather than from colon. American journal of surgery. Jul 2010;200(1):111-117.

20. Moody FG, Haley-Russell D, Muncy DM. Intestinal transit and bacterial translocation in obstructive pancreatitis. Digestive diseases and sciences. Aug 1995;40(8):1798-1804.

21. Swank GM, Deitch EA. Role of the gut in multiple organ failure: bacterial translocation and permeability changes. World journal of surgery. May 1996;20(4):411-417.

22. Berg RD. Bacterial translocation from the gastrointestinal tract. Advances in experimental medicine and biology. 1999;473:11-30.

23. Kouris GJ, Liu Q, Rossi H, et al. The effect of glucagon-like peptide 2 on intestinal permeability and bacterial translocation in acute necrotizing pancreatitis. American journal of surgery. Jun 2001;181(6):571-575.

24. Utomo WK, Narayanan $\mathrm{V}$, Biermann $\mathrm{K}$, et al. mTOR is a promising therapeutical target in a subpopulation of pancreatic adenocarcinoma. Cancer letters. May 1 2014;346(2):309-317.

25. Zordan A. Fluorescence in situ hybridization on formalin-fixed, paraffin-embedded tissue sections. Methods Mol Biol. 2011;730:189-202.

26. Rubinstein MR, Wang X, Liu W, Hao Y, Cai G, Han YW. Fusobacterium nucleatum promotes colorectal carcinogenesis by modulating E-cadherin/beta-catenin signaling via its FadA adhesin. Cell host \& microbe. Aug 14 2013;14(2):195-206.

27. Zulfikaroglu B, Koc M, Ozalp N. Candida albicans-infected pancreatic pseudocyst: report of a case. Surgery today. 2004;34(5):466-469.

28. Verma R, Dhamija R, Ross SC, Batts DH, Loehrke ME. Symbiotic bacteria induced necrotizing pancreatitis. JOP : Journal of the pancreas. 2010;11(5):474-476.

29. Aydin S, Isik AT, Unal B, et al. Effects of infliximab on bacterial translocation in experimental acute necrotizing pancreatitis. The Indian journal of medical research. May 2012;135(5):656-661.

30. Brook I, Frazier EH. Microbiological analysis of pancreatic abscess. Clinical infectious diseases : an official publication of the Infectious Diseases Society of America. Feb 1996;22(2):384-385.

31. Cherenfant J, Nikfarjam M, Mathew A, Kimchi ET, Staveley-O'Carroll KF. Completion pancreatectomy for treatment of a Clostridium perfringens pancreatic infection. Archives of surgery. Apr 2009;144(4):368-370.

32. Behrman SW, Bahr MH, Dickson PV, Zarzaur BL. The microbiology of secondary and postoperative pancreatic infections: implications for antimicrobial management. Archives of surgery. May 2011;146(5):613-619.

33. Michaud DS, Izard J, Wilhelm-Benartzi CS, et al. Plasma antibodies to oral bacteria and risk of pancreatic cancer in a large European prospective cohort study. Gut. Dec 2013;62(12):1764-1770.

34. Zackular JP, Baxter NT, Iverson KD, et al. The gut microbiome modulates colon tumorigenesis. mBio. 2013;4(6):e00692-00613.

35. Zackular JP, Rogers MA, Ruffin MTt, Schloss PD. The human gut microbiome as a screening tool for colorectal cancer. Cancer Prev Res (Phila). Nov 2014;7(11):1112-1121.

36. Farrell JJ, Zhang L, Zhou H, et al. Variations of oral microbiota are associated with pancreatic diseases including pancreatic cancer. Gut. Apr 2012;61(4):582-588.

37. Stolzenberg-Solomon RZ, Dodd KW, Blaser MJ, Virtamo J, Taylor PR, Albanes D. Tooth loss, pancreatic cancer, and Helicobacter pylori. The American journal of clinical nutrition. Jul 2003;78(1):176-181. 
38. Wohrer $S$, Hejna $M$, Raderer $M$. Helicobacter pylori and pancreatic cancer. A working hypothesis from epidemiological studies. JOP : Journal of the pancreas. Jul 2003;4(4):163-164; author reply 164.

39. de Martel C, Llosa AE, Friedman GD, et al. Helicobacter pylori infection and development of pancreatic cancer. Cancer epidemiology, biomarkers \& prevention : a publication of the American Association for Cancer Research, cosponsored by the American Society of Preventive Oncology. May 2008;17(5):1188-1194.

40. Lindkvist B, Johansen D, Borgstrom A, Manjer J. A prospective study of Helicobacter pylori in relation to the risk for pancreatic cancer. $B M C$ cancer. 2008;8:321.

41. Risch HA, Yu H, Lu L, Kidd MS. ABO blood group, Helicobacter pylori seropositivity, and risk of pancreatic cancer: a case-control study. Journal of the National Cancer Institute. Apr 7 2010;102(7):502-505.

42. Nilsson HO, Stenram U, Ihse I, Wadstrom T. Helicobacter species ribosomal DNA in the pancreas, stomach and duodenum of pancreatic cancer patients. World journal of gastroenterology : WJG. May 21 2006;12(19):3038-3043.

43. Manes G, Balzano A, Vaira D. Helicobacter pylori and pancreatic disease. JOP : Journal of the pancreas. May 2003;4(3):111-116.

44. Kostic $A D$, Chun $E$, Robertson $L$, et al. Fusobacterium nucleatum potentiates intestinal tumorigenesis and modulates the tumor-immune microenvironment. Cell host \& microbe. Aug 14 2013;14(2):207-215.

45. Chandrakesan $P$, Roy $B$, Jakkula LU, et al. Utility of a bacterial infection model to study epithelialmesenchymal transition, mesenchymal-epithelial transition or tumorigenesis. Oncogene. May 15 2014;33(20):2639-2654.

46. Gagliani N, Hu B, Huber S, Elinav E, Flavell RA. The fire within: microbes inflame tumors. Cell. May 8 2014;157(4):776-783.

47. $\mathrm{Xu} \mathrm{W}$, Yang $L$, Lee $P$, et al. Mini-review: perspective of the microbiome in the pathogenesis of urothelial carcinoma. American journal of clinical and experimental urology. Apr 15 2014;2(1):5761.

48. Shinohara DB, Vaghasia AM, Yu SH, et al. A mouse model of chronic prostatic inflammation using a human prostate cancer-derived isolate of Propionibacterium acnes. The Prostate. Jun 2013;73(9):1007-1015.

49. Bae $\mathrm{Y}$, Ito $\mathrm{T}$, lida $\mathrm{T}$, et al. Intracellular Propionibacterium acnes infection in glandular epithelium and stromal macrophages of the prostate with or without cancer. PloS one. 2014;9(2):e90324.

50. Yoshimoto S, Loo TM, Atarashi K, et al. Obesity-induced gut microbial metabolite promotes liver cancer through senescence secretome. Nature. Jul 4 2013;499(7456):97-101. 
Bacterial 16S rRNA (EUB338 probe) in-situ hybridization in resected tissue

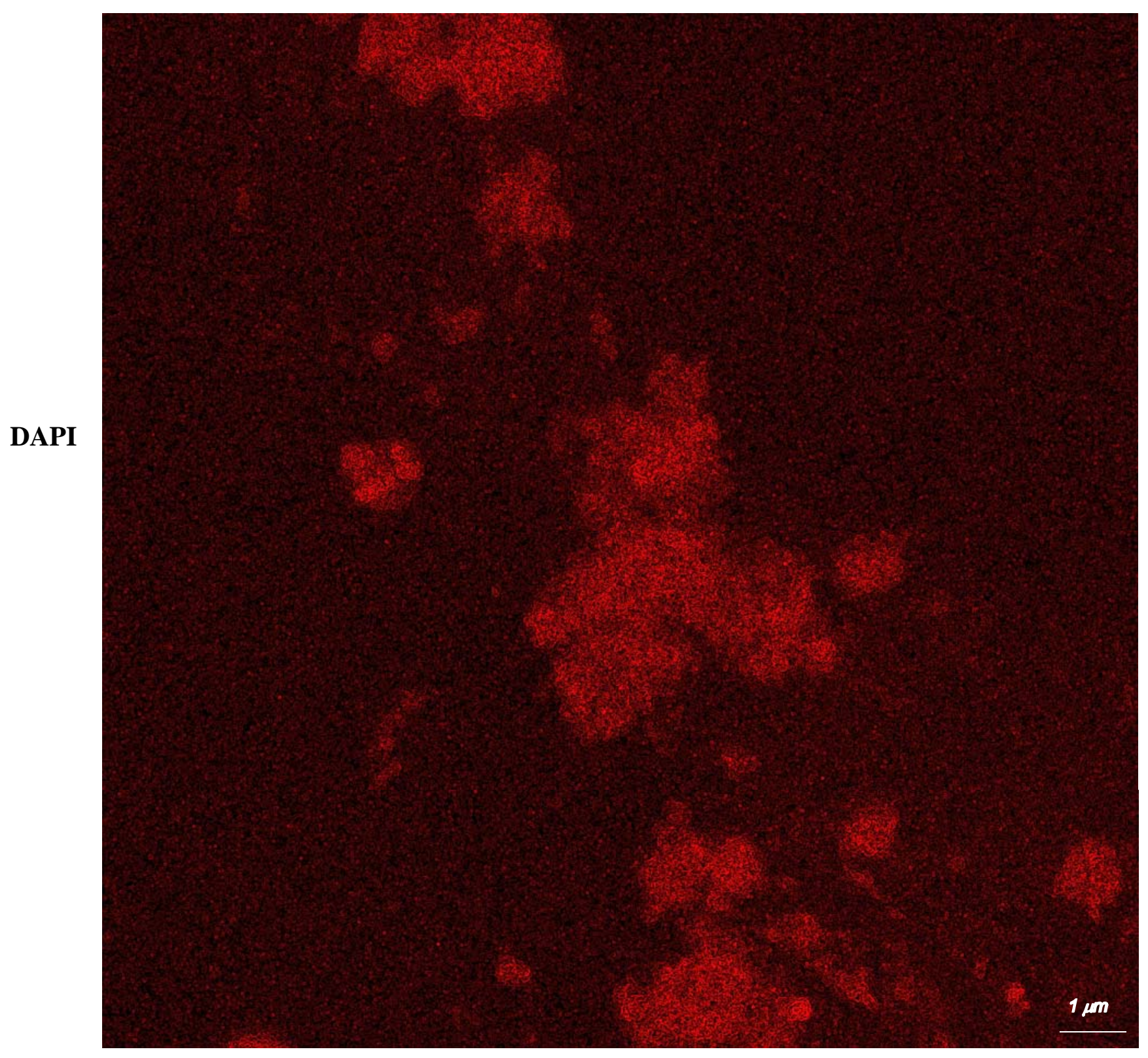




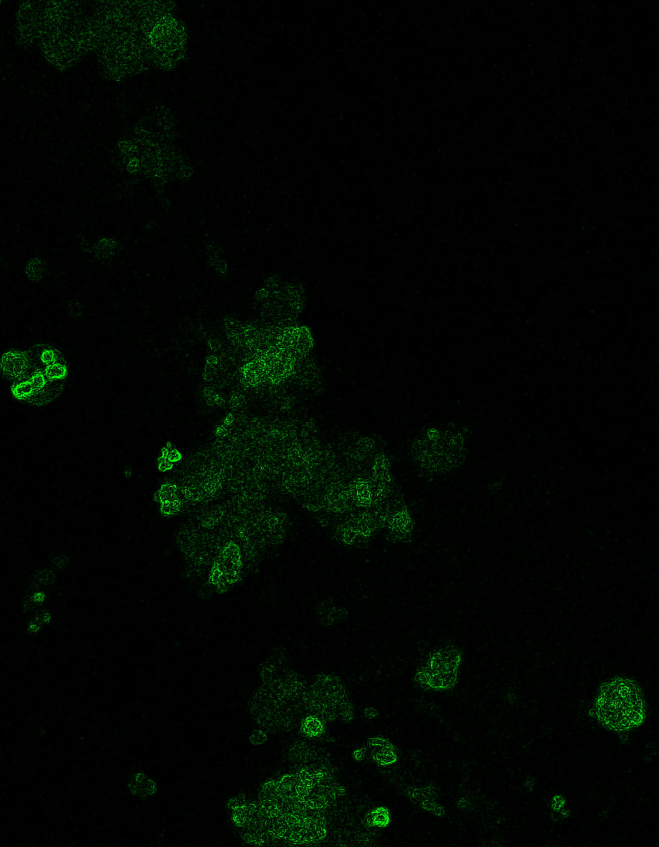





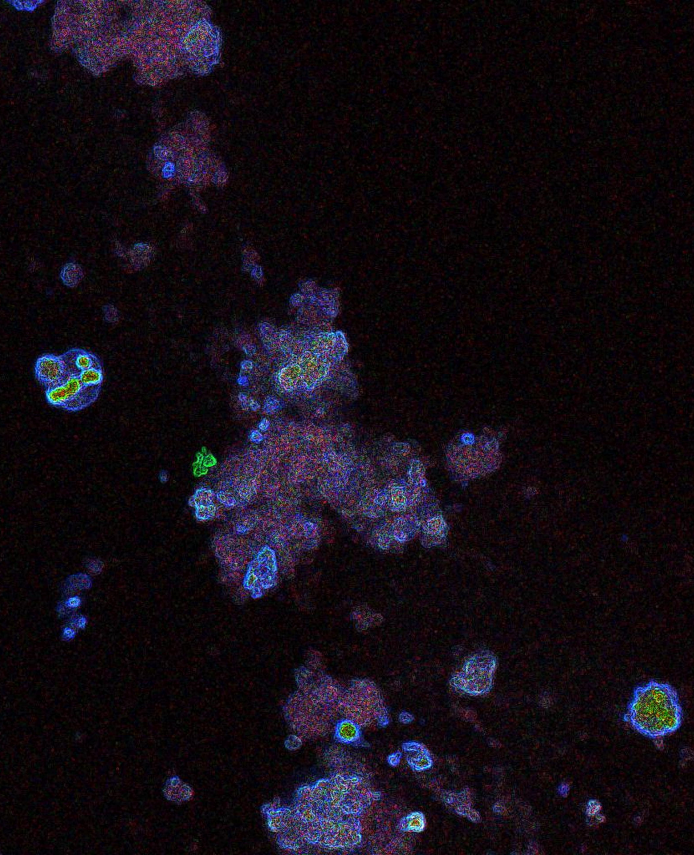

